\title{
Lost in Autonomy - Temporal Structures and Their Implications for Employees' Autonomy and Well-Being among Knowledge Workers
}

\section{Ari Väänänen ${ }^{1,2} \cdot$ Minna Toivanen ${ }^{1} \cdot$ Tea Lallukka ${ }^{1,3}$}

Received: 2 July 2019 / Revised: 23 March 2020 / Accepted: 6 April 2020 / Published online: 27 April 2020

(C) The Author(s) 2020

\begin{abstract}
Conceptual models based on the importance of work autonomy for employees' health represent important cornerstones in the occupational well-being and work stress literature. The objectives of this study were to 1) explore and understand the temporal conditions framing work among autonomous knowledge professionals, 2) describe how autonomy is experienced in knowledge work jobs, and 3) analyze the implications of current autonomy for well-being in knowledge work. The interview study consisted of 21 women and 13 men who worked in knowledge-intensive jobs in Finland. Analysis of the material shows that knowledge work is structured by different levels of transverse temporal structures: individual and social structures, and organizational and macrolevel structures. This creates a paradoxical nature of autonomy among knowledge workers, characterized by high task autonomy and intense socio-temporal interdependence. One can have strong autonomy and be tied at the same time. Unsynchronized time structures can lead to fragmented work, overwhelming work burden, and higher risk of mental health symptoms. It would therefore be advisable to establish collective temporal structures in organizations that create manageability and predictability. We conclude that models of occupational well-being and work stress should pay more attention to the social structure and temporal interdependencies that characterize knowledge work.
\end{abstract}

Keywords Knowledge work · Autonomy $\cdot$ Well-being $\cdot$ Time $\cdot$ Stress models

Ari Väänänen

ari.vaananen@ttl.fi

1 Finnish Institute of Occupational Health, P.O. Box 40, 00032 TYÖTERVEYSLAITOS, Helsinki, Finland

2 School of Social Policy, Sociology and Social Research, University of Kent, Canterbury, UK

3 Department of Public Health, University of Helsinki, Helsinki, Finland 


\section{Introduction}

\section{Interrelatedness and Autonomy in Knowledge Work}

Several influential models of occupational stress and well-being have defined work autonomy as a central factor (e.g., Carayon 1993; Demerouti et al. 2001; Frese 1989; Hackman and Oldham 1975, Karasek Jr. 1979). In these models, autonomy is assumed to have the potential to ensure motivation and performance as well as well-being (Stiglbauer and Kovacs 2018). Most of these frameworks were developed during the era of a strong industrial sector and when rather pre-structured office jobs were increasing in Western countries. The objective of occupational health researchers was to make work more decent and develop psychosocial resources to combat poor working conditions (e.g., Frankenhaeuser and Gardell 1976; Gardell 1971; Hackman and Oldham 1975). But how well do the conceptualizations inherited from the 1970s and 1980s suit current working life? What characterizes today's autonomy? What kinds of limitations and implications does it have?

When the information society was born, psychologically demanding and less prestructured jobs became more common, especially for highly educated professionals. In the twenty-first century, knowledge intensive work has become one of the dominating forms of working. Knowledge work is formed from knowledge and other systematically gathered information for application to practical problems. The work benefits greatly from information technology in identifying and solving problems (e.g., Alvesson 2001; Mazmanian et al. 2013 In most EU countries more than $20 \%$ of working age people are engaged in knowledge jobs (e.g., Brinkley et al. 2009; Statistics Finland 2016) and in most Western countries, the proportion of these jobs is rapidly growing (e.g., Zumbrum 2016).

For the most part, knowledge work is done by highly trained professionals working in upper white-collar jobs. Knowledge workers have been accustomed to arranging their own work and schedules themselves (e.g., Hellgren et al. 2008; Näswall et al. 2008) within flexible work schedules and usually a frantic work pace (Rosa 2003). Professionals' possibilities to affect their own work are therefore often better than those of other groups of workers (Sutela and Lehto 2014). Individual control of time and freedom to plan their time are very high in principle. From the perspective of occupational health, the question of scheduling and the management of freedom in knowledge work is increasingly essential. Knowledge work requires specialized expertise from various workers, whose tasks are based on mutual interdependencies. For instance, the development of a high-tech household product requires the expertise and collaboration of specialists: technical know-how, knowledge of materials, vision in terms of design, understanding of customer needs, expertise on cognitive usability, and an overview of cost structure. Usually, this type of work and working time are split into various work tasks, as these professionals work simultaneously in several ongoing projects. Interestingly, in a national survey of knowledge employees in Finland, more than two thirds of respondents reported high autonomy in relation to time management. However, half of them also experienced strong ties with various networks, which considerably limited their autonomy (Toivanen et al. 2016). This situation can be labelled tied autonomy, which is characterized by a high level of individual freedom to make decisions and plan one's work, but also by a high level of connectivity and temporal interdependency, 
because the work process itself is embedded in multiple social and organizational relationships (Väänänen and Toivanen 2018). In this context, autonomy may have a rather illusory character.

Knowledge work is usually intertwined with work done by others, clients' needs, and a changing work environment. Changes in the organization of work, activities in various networks, and the complicated and broadened dependencies of work tasks and employees restructure work in a new way and challenge the autonomy of knowledge workers (cf. Mazmanian et al. 2013; Von Nordenflycht 2010). Temporal co-ordination inevitably belongs within this collaboration, and work involves much negotiation related to the organization of time (e.g., Flaherty and Seipp-Williams 2005). Within the frameworks of work time, workers have multiple networks, which all have their own time frame (Cipriani 2013; Lee and Sawyer 2010). In this type of working life reality, collective temporal rhythms strongly form and direct activity (Southerton 2012). The first two aims of the study were to explore and understand 1) the temporal conditions framing work among autonomous knowledge professionals, and 2) how autonomy is experienced in these jobs.

\section{Autonomy, Temporal Conditions and Well-Being}

Recent meta-analyses using large working populations from various Western European countries have indicated that job autonomy had a modest impact on health outcomes, especially when examined with respect to serious, objectively verified health effects (e.g., Heikkilä et al. 2013; Kivimäki, Nyberg, Batty [...], for the IPD-Work Consortium 2012; Madsen et al. 2017). In addition, critical discussions in the field of work sociology (e.g., Ehrenberg 2010; Näswall et al. 2008) as well as in the field of occupational health psychology (e.g., Schaufeli and Taris 2014) suggest that the assumption concerning the beneficial impact of autonomous functioning at work on one's well-being might be too straightforward in the plurality of current information societies, in which autonomy is realized in a new working life context. It has been proposed that the different dimensions of work autonomy play a distinctive role in wellbeing (De Spiegelaere et al. 2016).

Especially since the late 1990s, occupational health studies have gradually begun to propose that the concept of work autonomy consists of certain dimensions. Most models propose that autonomy is related to work methods (how to perform tasks), decision-making (who makes the decisions) and time control (how schedules are arranged) (e.g., de Jong et al. 1999; Morgeson and Humphrey 2006). In addition, recent work arrangements related to virtual work and knowledge work have further challenged the adequacy of older occupational health models, as the beginning and end of a working day have become less fixed (Barney and Elias 2010). In knowledge work, high individual autonomy may also increase organizational disorientation (Langfred and Rockmann 2016) and lead to unsynchronized decision-making and adverse collective well-being (Morgeson and Humphrey 2006). Taken together, it seems that the beneficial role of global autonomy in working life has become less evident, while information processing and the project-type nature of current jobs has highlighted the importance of mutual interdependencies and time-synchronies in autonomous work. However, most previous research has focused on global job autonomy using predefined quantitative scales without intending to analyze the ambivalence or 
psychological burden arising from the tension between autonomous status and strong temporal/social interdependence (Parker et al. 2014; Stiglbauer and Kovacs 2018). It seems likely that this tension can cause feelings of insufficiency and stress (Mazmanian et al. 2013).

In line with these ideas, some researchers have suggested that time-related problems are one of the critical factors affecting well-being among contemporary employees (e.g., time pressure, time speed-ups, tight deadlines, see Ala-Mursula et al. 2006; Moen et al. 2013; Nätti et al. 2011; Shultz et al. 2010). It is important to note, however, that earlier research in occupational health sciences has mainly focused on control over the duration (time control facet of autonomy) or the tempo of work (work pace facet of autonomy). These studies show that control over working time and the selfdetermination of work pace have mostly positive associations with well-being (Kompier 2003; Nijp et al. 2012). Poor control over working time has been associated with psychological distress (Ala-Mursula et al. 2002), and low perceived control of working time has been linked to health complaints (Adams and Jex 1999). In contrast, high schedule control has predicted work engagement (Swanberg et al. 2011). Interestingly, a natural experiment in a large work organization showed that improved structuring of working time promoted subjective well-being among white-collar employees (Moen et al. 2011). However, although the social connectivity and synchronization of time has been identified as a central dimension of time structure among adults (Southerton 2006), knowledge workers in particular (Toivanen et al. 2016), the synchronization of time in a network of actors and its influences on well-being has remained poorly understood in the occupational health literature. More specifically, earlier research has neglected to pay attention to how socially determined time structures may frame knowledge work, how knowledge workers themselves experience the tension between high autonomy and high time-related dependency, and how these work characteristics may influence their well-being. In line with this, recent theoretical openings propose that current occupational health research should place considerably more empirical focus on the role of tied autonomy, as studies of occupational health psychology have not sufficiently understood the Janus-face of tied autonomy (Väänänen and Toivanen 2018). Therefore, the third aim of this study was to analyze the implications of current autonomy for well-being in knowledge work.

Because qualitative methods are particularly suitable for exploring new phenomena and elaborating on existing theories (Schonfeld and Mazzola 2012), we conducted an in-depth qualitative analysis of the temporal conditions of knowledge workers and the nature of their work autonomy. This approach allowed us to make less controlled observations regarding time-dependence, autonomy and well-being in this work.

\section{Research Questions}

We formulated three research questions that specify the main aims of the study.

Research question 1 (RQ1). How do temporal conditions frame knowledge workers' work?

Research question 2 (RQ2). How is the autonomy realized and experienced in knowledge work linked to various ties and networks?

Research question 3 (RQ3). How is the new nature of autonomy reflected in wellbeing among knowledge workers? 
Our aim was also to rethink how the changing nature of work should be taken into consideration in the development of occupational health models and organizational interventions.

\section{Methods}

The material for this study was collected as a part of a research project called A Synchrony of Timelines in Specialist Jobs led by the Finnish Institute of Occupational Health (FIOH). To ensure the systematic and rigorous application of data gathering and analysis methods, and in order to answer the research questions, we carefully planned the generation of data from the interviews (Silverman 2001). The interviewees were recruited for the project by certain labor market organizations (SPECIA [Experts and Managerial Professionals Association], Social Science Professionals, The Federation of the Finnish Media Industry). A total of 95 persons volunteered to participate in the study. Because we used a combination of the grounded theory framework and the theoretical ideas developed by organizational researchers (e.g., Orlikowski and Yates 2002), health sociologists (e.g., Ehrenberg 2010) and occupational health scientists (e.g., Stiglbauer and Kovacs 2018) broad sampling was appropriate. The aim was to obtain as much variation as possible to identify temporal conditions among knowledge workers, and to understand the role of autonomy and well-being (Elo and Kyngäs 2007; Strauss and Corbin 1998). The criteria for selecting the interviewees were the difference in their backgrounds (age, gender, sector of employment, occupational position) and the nature of their current work (knowledge-intensive work), including both supervisory level positions and non-supervisory positions. Six researchers from FIOH conducted semi-structured interviews of 34 participants, which included openended questions. Data collection ceased when the research group reached the consensus that no new information on the nature of work, the time-dependencies in knowledge work, the concept of autonomy and the background of occupational well-being was being acquired (Little et al. 2015). Although most interview questions and topics were predefined and based on reading the existing literature (Wilhelmy et al. 2016), the interviews were designed so that the interviewees also had the opportunity to describe their work and its characteristics in a free manner and bring new important topics to the discussion.

The interviewees represented different occupations (e.g., research, communication, public administration, and education) and their titles varied (e.g., designer or planner, specialist, project manager, publicist, and chief of training). A greater number of women were interviewed, as $80 \%$ of the volunteers were women and their occupations varied considerably. Overall, more women (52\%) than men are knowledge professionals in Finland.

The interviewees consisted of $21(61 \%)$ women and $13(39 \%)$ men. Twenty-three percent of the interviewees were under the age of 35 years, $26 \%$ were in the age range of 35-44 years, and $41 \%$ were 45 years of age or older. Most of them (91\%) had a university degree, $38 \%$ worked in the private sector, $32 \%$ worked in the public sector, and $29 \%$ worked elsewhere, for example, for associations or universities. Most of the interviewees worked in Helsinki or its close surroundings (82\%), held permanent jobs $(85 \%)$ and worked full time $(94 \%)$. Four of the interviews took place over the phone, 
and the rest were done face-to-face. The interviews lasted 45-120 min, were in Finnish, and were all recorded and transcribed. They were conducted in 2014-2015.

The interviewer first asked general questions about the background of the participant and their job. Due to the interdisciplinary background of the project, the interviews consisted of various themes such as typical day/week/year, digitalization, work burden, work tempo/rhythm, time scheduling, control over work, planning one's work, time challenges at work, changes at work, interdependencies, and collaborators. Each theme was covered by asking several sub-questions (e.g., "Please describe your typical working day", "How are the schedules of your working day formed?", "What are the biggest challenges related to time management in your work?") which were mostly decided beforehand. However, each interview also consisted of free open-ended sections in which the interviewer allowed and stimulated discussion on the topics related to knowledge work and its typical nature without using pre-defined questions.

Data analysis consisted of four stages. The first and second authors of this manuscript were involved in all these stages. First, in the descriptive stage, they read though all the interview transcripts and identified the key aspects of knowledge work and its nature. They detected more than ten descriptive themes frequently mentioned in the interviews (e.g., fragmented nature of work, time control from the individual's perspective, interdependencies in knowledge work, management of time and autonomy at the workplace, other topics related to time and control over time at work, responsibilities, and self-managed autonomy).

In the second stage, they read though the texts classified according to analytical categories using theoretical ideas from previous research. At this stage, they reorganized the materials from all 34 interviews into more focused categories. The aim was to elaborate on the focal dimensions and tensions that influence knowledge workers' time management and the overall nature of autonomy. For instance, they discovered that for most interviewees, work autonomy included a strong tension between individual independency and social dependency.

The third stage of the data analysis was crucial for the final analytical framework of this article. The interview material showed that the key structural dimensions of timerelated autonomy were in line with the typology of social time developed by Lewis and Weigert (1981). This finding helped reorganize the data into four different structural dimensions (individual, social, organizational and macrolevel), specify the temporal demands of knowledge work and analyze the possibilities for autonomy in such work.

Finally, in stage four, to expand the contribution of the study to occupational health research and model development, four structural categories of time were analyzed, from the perspective of autonomy and formation of well-being and stress in knowledge work. During this stage, the authors assessed and reflected in particular on how traditional models of occupational well-being fit the analysis of autonomy and wellbeing in knowledge-intensive work (Catanzaro 1988; Payne and Williams 2005).

To guarantee the reliability of the research process, the first two authors directed the process and the collection of interview material. These authors were responsible for the analysis and classified all the interview material. To guarantee the homogeneity and consensus of the classifications between the researchers, the coders met in joint coding meetings to compare individual codings and discuss discrepancies (Wilhelmy et al. 2016). The coders were attentive to how the classifications (e.g., levels of time structures) were related to existing research and how previous research could be used 
to identify new categories (Locke 2001). The analysis was designed so that reliability checks were conducted several times during the analysis. The main findings of this paper are based on this interactive process. For the purposes of this article, the first and second author focused on how the categories associated with time-related challenges were interrelated with the concept of autonomy and the well-being categories.

\section{Results}

The results of the interviews are divided into two sections. Section 3.1 presents the results dealing with RQ1 and RQ2. The findings describe the temporal frameworks of knowledge work and how autonomy is experienced within these frameworks. Section 3.2, dealing with RQ2 and RQ3, further analyzes the nature of autonomy and discusses the implications for well-being. Figure 1 summarizes the main findings.

\section{Time Structures for Knowledge Work}

Individual Structures: Personal Time and Schedules According to previous research, the creation of new innovations and knowledge cannot be forced; instead one must let it happen without a schedule (e.g., Hakkarainen et al. 2012; Noonan 2015). The responses of the interviewees showed a strong belief in the need of uninterrupted and unscheduled thought-time in knowledge work. Many of the interviewees spoke of reserving time for themselves, their own expertise, and engrossing issues (see also Liao et al. 2013). However, the interview material clearly showed that knowledge work is difficult to schedule.

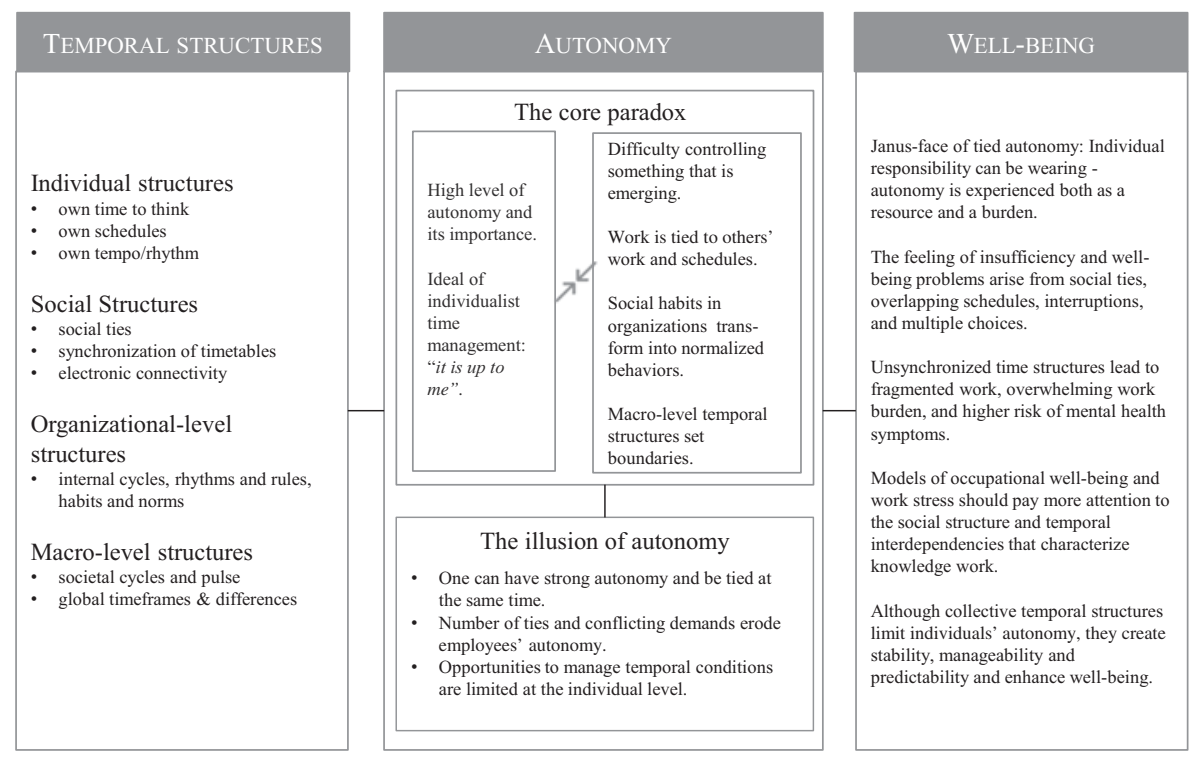

Fig. 1 Lost in Autonomy - temporal structures and their implications for employees' autonomy and wellbeing among knowledge workers 
I've noticed, that I don't ever know what it will take.... Even some small detail, one solution that can take an inordinate amount of time. Then again some big concept can be clear just like [...] Of course, there's the continuous feeling that, is it good enough and is it now thought through to completion. (male, private sector).

Our interview material showed how difficult it is to control something that is unpredictable. The interviews indicated that it is a question of a job without a schedule. Knowledge workers often work with "unknown boundaries", as Hakkarainen et al. (2012, p. 4) have remarked. There is an indistinct picture of the future, but it seldom goes as planned.

Interviewees had their own schedules (i.e., mental time) that they could not necessarily regulate. In neuro-cognitive psychology, the positive consequences of this type of unregulated "mind-wandering" for creative thinking has increasingly been emphasized (e.g., Baird et al. 2012). In our material, the interviewees spoke of how mental work tended to spread out to broader areas (both spatially and temporally) when their minds focused on work-related issues throughout the day and ideas occurred outside the workday.

And all the time, those thoughts are on my mind... if I have to lead a new seminar two weeks from now or training in some new theme that I've been getting ready for a long time, then, of course, it's in my head all the time and I check out my surroundings accordingly and still try to always search for more information. ... It is on my mind and my subconscious is also working these things over and they don't disappear. (female, other sector).

Although, in our interviews, many of the professionals felt that keeping to a schedule was a challenge in their work, they rationally intended to schedule it and set objective timeframes. For many of the interviewees, controlling their own time was a matter of shifting blocks from one place to another; others attempted the keep strictly to their set schedule. The professionals seemed to be autonomous with respect to being in control of their own schedule.

We have an Outlook calendar, and I try to schedule my worktime myself. Of course, if I know that someone needs immediate help. Then there is the reserve of my own time for that, so that no meetings will interfere. And then, of course, for things that need priority, I try to plan for them myself. In other words, there are some that must be done this week, I reserve time for them too. (male, public sector).

The interviews illustrated how one's own time for thinking created a tense relationship with the objective schedules in the structure of individual time. One's own time was, by nature, a subjective process time tied to a task or situation, whereas scheduling was strongly based on physical time measured by a clock. Nevertheless, an attempt was made to make them compatible, even though it was difficult to schedule thinking.

Within one's own individual time structure, knowledge work seems to be very autonomous: experts deciding on their own schedules and order of work tasks. In this manner, knowledge work in the 2010s greatly differs from the nature of work done in mechanized production, in which enhancing the possibilities for even restricted autonomy (e.g., breaks, rotation) was an adequate objective because the work itself was fundamentally tied to machinery and assembly lines, with a certain tempo and place. Compared to the jobs of the 1960s and 1970s, potential control over one's work was high among the professionals interviewed, and continuous prioritization between tasks was an essential part of their work. In contrast, a lack of autonomy as such was not 
considered a problem from the perspective of individual time structures. At the level of individual behavioral options, a high level of autonomy was repeatedly recognized.

Social Structures: Ties, Arbitration and Synchronization In our material, the interdependencies related to social activities and time management became apparent and had the power to regulate time (see, e.g., Ketokivi 2014). Our interviews showed how employees' work was tied to others' work and others' schedules, and there was collaboration with other agents, the schedule being agreed upon for both work and home - time was tied. Sometimes needed papers are bogged down on a co-worker's desk, the job needs the attention of a person with a certain specialty, or decisions or signatures are still missing. At worst, even one link being behind schedule stops the entire work process.

The hierarchy ... who approves certain things, that is this text now ready to be published and is this text ready to go to the next person, these kinds of bottlenecks, and one doesn't know what other things are happening in some other's work, or in what part of the world this person is. This slows down a lot, still no approval, instead it's put off until next week. ... (female, private sector).

Our interviewees repeatedly emphasized how joint meetings and other mutual times that have been agreed on form strong temporal frameworks for one's own schedules. Schedules and meetings are set far in advance, and the days begin to be paced accordingly. The temporal framework and timeline set for project work are often based on a common project plan.

Often, creating a common schedule - time synchrony - was not easy for our study participants. The more people involved, the more difficult it is to build a mutual structure. People are busy, "everyone's diary is overbooked" as one interviewee described. The difficulty to agree on mutual time structures and meetings came up in all of the interviews.

... there's one matter to agree upon, the project depends on getting the organization's board to meet and then we can begin from there. It has already been waiting since December and still the date hasn't been set for when we can begin. Everyone's in such a hurry that we just can't get them to sit down at the same table. (female, private sector).

Time synchrony can be challenging for functional objective schedules, but also with respect to a person's mental time. Our interviewees commented that although colleagues were often physically in the same place at the same time, they were not really present. The challenge arises of how to get people at the same place at the same time and also ensure that they are all mentally aware of what is currently going on.

People have experienced or maybe become frustrated, which is certainly true for everyone in today's world, when you're talking about something, present are 20 people and half of them are glued to their own laptop and the rest are focused on their phones, and when you try to explain something that will inspire participation and excite them. And everyone just stares at something and punches a screen. (male, private sector).

The preceding quotation also describes the extent to which the social structure has become electronic. Digitalization has supplied specialists with an electronic structure that partly sets the pace of their activity. Electronic systems make real time functioning possible; one's own work can be done even in meetings, as the preceding quotation shows, but, at the same time, digital systems create new work demands, work interruptions, and situations in which several tasks are done simultaneously (cf, Chesley 
2014; Wajcman and Rose 2011). In many of the interviews, it was stated that email had to be read many times a day, and often there was a reason to reply immediately. Otherwise the email became flooded, and important matters might be buried.

Many interviewees emphasized that they had attempted to limit their reading of emails during the workday. Especially arranging time for thinking often requires the shutting down of various communication channels. The search for a peaceful time to work is one of the primary characteristics of the individualized attempt for control that marks knowledge work, and it exemplifies the threat to well-being (e.g., irritation, cognitive overload, interruptions) that is formed despite the autonomy of the work. Email and other electronic channels offer freedom, but they also intensify and fragment knowledge work (cf., Chesley 2014; Mazmanian et al. 2013).

Structures at the Organizational Level: Quick Cycles and Reactions Organizations coordinate their workers' activities using common schedules. Earlier such coordination generally belonged to management or the foreman (Blount and Janicik 2001). According to our data, interviewees were responsible for planning their own activities and schedules, creating a common temporal structure within work community is challenging. It appears that an organization's temporal structure was often formed through surreptitious activity. As the quotes illustrate, within organizations there may be, for example, a habit of strongly clinging to the present, to respond to emails immediately, work overtime, or stretch the day as needed.

When I went there to work, I wondered at the fact that really very few used even an Outlook calendar. ... Then I realized that it was because these people were so very "hands on" and did everything right away and they didn't bother to stop and write anything down. (male, private sector).

This quote describes the organizational habits related to overtime, reactions, and time orientation. It seems that these habits can form guiding norms that determine when and how work is done at a workplace. From an individual's perspective, this characteristic of knowledge work strongly frames the potential of using one's autonomy, and workers often feel that they are left alone with timetables and prioritizing. In addition, each organization acts in a certain field; the market and various regulations affect organizational activity and its temporal structure.

\section{Macrolevel Structures: The Pulse and Cycles of a Broader Operational} Environment According to our interviews, knowledge workers have to make adjustments, because their work, like society, has its own cycle and pulse." Society is still built, for example, around the idea of eight to four", as one of the interviewees expressed it. Each day of the week can have its own temporal feature; the year is structured according to public holidays. Different seasons can be related in different ways to temporal condensing, as the following quotation shows:

I think that people stretch the weekend either at its beginning or its end so that others are easier to reach. People abroad are easier to contact from Tuesday through Thursday. Then, maybe there are these client meetings that maybe mean more work or [...] I need to think about the use of my own time and be flexible because the client's time is more important. (female, private sector).

Broader operational environments have other cycles as well. According to our material, various institutions determine the temporal structure and affect the self- 
management of knowledge work. For example, political decision-makers and various other administrative areas have their own, often inflexible, temporal structures. In addition, the pulses and cycles of global economy have their impact:

... this global economic market, that no one can control, but which forces people and organizations and countries into such a continuous contest with each other and it just gets stronger and stronger and screws tighter everywhere. (male, public sector).

Many of the interviewees also talked about how their own work schedules are especially intertwined not only at the national level, but also with global temporal structures.

And when activity crosses the borders between countries, it is met with national culture-related temporal structures and habits, as well as changes in time zones.

According to the interviewees, macrolevel structures seem to be strongly objective temporal structures that are outside their area of influence. They just had to adjust their work to fit them. Even though work is experienced as being autonomous and offering independency, various ties that cross borders add structures to autonomy and possibilities to use it. Nevertheless, the situation is not considered to be the traditional problem affecting the right to have one's say and constricted control as in factory work; instead, from the traditional perspective of industrial work, the potential for job autonomy is very broad, but its use is being restricted by a macro-structural framework in which knowledge workers are attached.

To summarize, knowledge work is framed by individual, social, organizational and macro-level temporal structures. Our results suggest that these frameworks regulate the realization of autonomy and restrict the actual autonomy of knowledge professionals (RQ 1 and 2.)

\section{Occupational Well-Being in the Context of Temporal Structure and Autonomy}

Our interviews revealed how every day employees are confronted with several temporal structures at the same time. Work is fragmented into several pieces; it is comprised of different episodes, such as participating in meetings, making telephone calls, emailing, reading and writing (see also Wajcmanin \& Rosen, 2011). Different episodes and temporal structures have various expectations that can be discordant, conflicting, or offering alternatives (Orlikowski and Yates 2002).

The resonance of the temporal structures was apparent in our interview material. Work was structured into many kinds of time windows, work" was just terribly disorganized". In practice, in the realm of work, their own expertise and its development seemed to be challenging in the framework of shattered temporal structures. Many of those interviewed mentioned how surprises changed the course of their day, abrupt fast events messed up the prioritization, and important matters had to be put aside. The interview material presented the picture that work often consisted of various reactions to emerging problems. Often it was especially social temporal structures related to interaction that interfered with individual structures.

Of course it was those continual interruptions that come then. Maybe in the form of email, telephone calls, co-workers' questions. Or then, for example, in such situations that often involve many invitations to meetings from the organization's various levels that can't be handled by myself, so how do I reserve enough room in my own calendar 
so that I can take care of the week's most critical matters, even though everything else crashes around me. (female, other sector).

Interviews indicated how knowledge worker's social time becomes stratified. Interactive time determines personal time, especially if people's own temporal structures has become strongly embedded with others. As knowledge work and organizations have become multifold and work has changed, focusing on international and networking communication, especially in the 2000's, their personal time and opportunities have drifted still further into new types of structures in which they are again re-defined and re-structured.

In almost all of the interviews, the knowledge workers nevertheless emphasized the autonomy of their own work and its importance. They also asserted that the management of their own time "is up to me". Many of the interviewees emphasized their own self-reflection and activeness. The acknowledgement of one's competence was viewed as a starting point. People should understand how much is suitable for themselves; they should know how to put restrictions on their work, should simply make time for their own work. "A sense of self-protection" is needed.

But I now also understand that there's never enough time, ever, that that is a utopian situation because, in this type of work, there just aren't any boundaries, you can do as much as you want as fast as you want. So the only way is to determine yourself what's to be done when, and talk it over with yourself about where you are, where you can move in safe waters.... And not worry too much about quality, that there just has to be some sort of boundary, that this is the way it is, and that's it. (female, other sector).

Setting boundaries for work and determining the amount of work suitable for oneself does not seem to be easy. The interviewees often used such expressions as "I should" and "I have tried". Many of them had a clear concept of what they should do so that they could fare better, but the manner in which to achieve their goal was, for some reason, out of their reach. Many of the knowledge workers were mostly on their own in setting the structures of different structures. Management or the boss was "pretty much in the dark about workers' tasks"; no one had actually told them what a knowledge worker should do and felt it was difficult to determine whether the job was being done or not.

If I had managed to have a clearer calendar right from the start of the project I might not have burnt out in the spring (male, private sector).

The interviewees who emphasized independence also stressed the individual's competence to manage time and stress. The construction of time is, however, experienced as a social process that an individual can seldom change alone or even manage the surrounding temporal structures (Orlikowski and Yates 2002). The demands of others, the great amount of work and number of ties took away the feeling of autonomy. Autonomy could be crushed if one's own work became uncontrollable and chaotic, even though, in principle, the decision-making was individual. The autonomy had an ambiguous character due to its continuous relatedness.

... for me, management is associated with what I can think about my own work and realize it in practice so that it's its own master, not just so that it's a matter of just reacting. ... Or so that it's not just my own work all the time but instead it's a reaction to others' requests or demands. ... It is important to keep in mind the main focus in order to avoid drifting into some minor issues. (female, other sector). 
With the use of electronic equipment, workers can work where and when, as long as they are flexibly available to their colleagues and other associates when the need arises. However, this type of contact easily becomes compressed and escalates so that, once again, autonomy is narrowed and work intensified (Mazmanian et al. 2013; see also Chesley 2014).

On the one hand, the interviews depict the independence of work, one's own responsibility, and, on the other hand, the illusion of autonomy. The control of individualistic work as being autonomous was turning into uncontrolled running to meet a minute-by-minute schedule. Often worktime spread past normal workhours, and cognitive pressure easily remained in place. This situation is also reflected over work contexts, as shown in the following quotation:

[...] sometimes there are such weeks that everything piles up and there are impossible schedules and such demands that I have to be ready. And then in that week there's also all kinds of other needs to hurry, and I have a kind of robot-like feeling. In other words, I'm pulled in all directions ... In the evening I think about everything I need to put reminders about into my phone so that I'll remember tomorrow to do something. And it may be that, by Friday I've such a feeling that I'm really not able to forget about the week, so I sleep really restlessly. And in the evenings I'm so tired [...] There can be some weeks when I'm really exhausted, going from meeting to meeting with a minuteby-minute schedule and thinking about how I can possibly get everything done. (female, public sector).

In this manner, autonomy that characterizes knowledge work leaves people doing work handily on their own. The hectic rhythm of work is easily reflected in psychological and somatic well-being. In many interviews, mental load, exhaustion, and sleeplessness creeped up. The core nature of work is linked with the social ties and networks framing the workdays and one's tasks. Under these circumstances, the development of an individual's work autonomy does not guarantee well-being. The feeling of insufficiency arises from the social ties, overlapping schedules, and choices. The trap is set by the interface between individual responsibility and numerous social ties, so that, along with work results, endurance is considered to be the responsibility of the individual. Given this, it becomes understandable that the "autonomous" knowledge work can produce both positive (e.g., high sense of personal accomplishment, strong motivation, low absenteeism) and negative (e.g., limitless stress, burden of decision-making, tenseness) individual and organizational consequences.

To summarize, temporal interdependences and conflicting demands compose a tied nature for autonomy in knowledge work, which can be wearing for occupational wellbeing. Simultaneously, strong autonomy at work frequently leaves people alone and can be burdensome (RQ 2 and 3.)

\section{Discussion}

This interview study of knowledge workers, focusing on the time-related dimensions of work autonomy and the interrelationships between structures and individuals, pinpoints new avenues through which occupational health research may correspond to the organizational reality lived by millions of employees. The findings show how various temporal structures influence knowledge work (RQ1). They also reveal how 
knowledge work has a paradoxical character. It contains a high level of autonomy, but activities are connected to different schedules, structures, and time windows (RQ2). Finally, the results indicate how the role of autonomy in well-being is highly complex in the context of knowledge work: it can be both a resource and a burden (RQ3).

Our research proposes that knowledge professionals may have a specific composition of work-related well-being, which may be connected to the limitless nature of their work. Earlier studies show that work-family conflicts and sleep problems are common side effects on the upper level of the occupational ladder, where work is often openended and self-directed (Rugulies et al. 2012; Väänänen and Toivanen 2018). The findings also indicate how often the pivotal occupational well-being models developed in the 1970s and 1980s do not adequately reflect the nature of knowledge work, nor are they suitable as a starting point for developing today's knowledge work. This result needs more research attention, as nearly a quarter of all Western workers are employed in the type of knowledge work described, and their number is increasing. Our findings suggest that models of occupational stress and stress management should focus more on how "tied autonomy" and other typical characteristics of knowledge work are related to the common social pathologies of current working life. Chronic overactivation, concentration problems and poor recovery are serious risk markers and are likely to lead to various health problems.

Theoretical Implications Traditional models of occupational well-being are based on thoughts of formalized work that should be enriched and humanized (e.g., Frese 1989; Hackman and Oldham 1975; Karasek Jr. 1979. The idea of an increase in autonomy and decision latitude among workers has been an essential part of developing workplaces. It has often signified a transition away from the direct control of the management. As knowledge work has spread and developed, a growing number of employees have moved from industrial production models to models characterized by various types of multi-level networks, temporal structures, loosening management control and increasing self-determination. In this form of production, the lack of decision latitude is not a problem as such; instead, different temporal structures and networks are intertwined around autonomous workers so that in many cases, autonomy becomes an illusion. However, the impact of enabling and restricting structures for individual employees has been poorly understood. In relation to the organization's management and supervisors, although independence is high and one can decide on how work is performed, various interrelationships and temporal interdependences considerably limit this autonomy. These ties that transform autonomy in knowledge work should also be considered in research. For instance, earlier surveys have assessed the extent to which individuals are able to control their work schedules. Based on our results, it would be theoretically reasonable to also assess the extent to which others influence one's own schedules.

To advance the models of organizational well-being and work stress, we combined theoretical discussions from organizational theorists (organizational time, interrelatedness), work sociologists (knowledge work, intensification) and occupational health scientists (complexity of autonomy, well-being). According to our results, occupational health researchers should acknowledge these structural influences and develop theoretical approaches that more adequately capture the built-in complexity of contemporary work. New ideas for studying the interplay between the individual and structural 
components of work in the construction of well-being may be found in research on social networks (e.g., Bizzi 2017), relational interdependence (e.g., Billett 2006) and in studies of time structures (e.g., Orlikowski and Yates 2002). The paradoxical nature of autonomy means that psychosocial factors at work may have distinctive meanings and impacts, depending on the social, organizational and occupational context. From the perspective of the transferability of the findings, this means that these results are not likely to be generalizable in more pre-structured jobs or jobs involving less collaboration and mutual interdependencies. It is also possible that the role of autonomy is different in more collectivist or high-power distance countries (e.g., Liu et al. 2011). In addition, our study mainly focused on the temporal dimensions of autonomy and gave other aspects of autonomy less attention. It would be important to also understand the problematic nature of other dimensions of autonomy (e.g., work methods, decisionmaking). Finally, our study concentrated on the experiences of various individuals working in different workplaces. To fully understand the collective nature of tied autonomy we need to focus on some specific teams and/or networks and observe their interdependencies, collective rhythms and social well-being.

Practical Implications This study suggests new ideas for organizational development and interventions that are more sensitive to the facets and challenges of knowledge intensive organizations. From the perspective of promoting occupational well-being, activities attempting to develop individual integrity and autonomy can end with results that are the opposite of what was intended. From the individual's point of view, the weight of a choice in a tightly restricted work rhythm can feel spurious when the structure has been decided elsewhere. Accordingly, from the point of view of the work organization, a lack of a collective structure may drive the organization into a fragmented and disorganized situation. Both well-being and organizational efficiency can be in danger if the complexity of timelines and the multidimensional social nature of work are not considered. It seems plausible that the stronger temporal structures of current knowledge work do not necessarily decrease employees' autonomy but increase it by synchronizing activity and creating a common rhythm. It would therefore be advisable to establish collective temporal structures and limits in organizations, which create stability, manageability and predictability (see Hernes 2004; Slawinski and Bansal 2015). Shared and mutually agreed silent times in workplaces and certain weekdays for teleworking or meetings are examples of these kinds of organizational arrangements. To summarize, developing the well-being of network-dependent knowledge workers does not necessarily require increasing the autonomy of various individual workers; instead it means dealing with the deficiencies of collective structures.

Future Studies These results suggest that the occupational, organizational and technological changes related to the structural transition of working life have a clear impact on the core concepts of occupational health psychology, such as work autonomy. They imply that future studies of occupational well-being would benefit from the bold use of the multidisciplinary perspective from various fields of social and critical psychology, sociology and organization studies. For instance, the ambiguous role of autonomy has been previously addressed in critical psychology (Schwartz 2005) and there has been considerable discussion on the "weariness" of autonomous individuals in Western societies in the sociology of mental health (e.g., Ehrenberg 2010). In this manner, our 
study further specifies and develops some of the earlier critical remarks in the field of occupational health (e.g., De Spiegelaere et al. 2016; Muntaner and O'Campo 1993; Newton 1995; Schaufeli and Taris 2014; Smollan et al. 2010). Overall, a determined and well-planned application of interdisciplinary approaches would likely enhance the novelty and practical implications of work stress studies and occupational health psychology in general. This signifies a challenge in terms of research tools. For instance, appropriate quantitative measures could be developed that would enable the investigation of this construct by measuring the co-occurrence of independency and interdependency, and the actual possibilities to execute autonomy.

We conclude that knowledge-intensive jobs normally have enough autonomy at the level of the individual's tasks in contexts in which supervisors play a smaller role in defining work. However, social and organizational relatedness frames these jobs and gives the work its typical nature. Relationships, ties and tight time frames in different directions challenge stress management and occupational well-being. Consequently, work autonomy is often rather illusory. We hope that this study will add to the growing research that is developing a more detailed and nuanced view of the relationship between social dependency, autonomy and well-being in current working life. Given the radical changes in working life, it is not surprising that the traditional occupational well-being models focusing on an individual's autonomy and maximum level of self-determination at work no longer function in knowledge work characterized by social structure and temporal interdependences. Although simple linear models (e.g., higher autonomy $>$ higher wellbeing) may be attractive in their simplicity, they may be poor guidelines for developing organizational well-being and theories of occupational well-being in today's labor market. Knowledge work calls for the consideration of the multidimensionality of autonomy and attention to the social and interdependent nature of autonomy itself.

Acknowledgements AV is supported by the Academy of Finland (Grant \#319200). TL is supported by the Academy of Finland (Grants \#287488 and \#319200) and by the Finnish Work Environment Fund (Grant $\# 117308$ ).

\section{Compliance with Ethical Standards}

Conflict of Interests On behalf of all authors, the corresponding author states that there is no conflict of interest.

Open Access This article is licensed under a Creative Commons Attribution 4.0 International License, which permits use, sharing, adaptation, distribution and reproduction in any medium or format, as long as you give appropriate credit to the original author(s) and the source, provide a link to the Creative Commons licence, and indicate if changes were made. The images or other third party material in this article are included in the article's Creative Commons licence, unless indicated otherwise in a credit line to the material. If material is not included in the article's Creative Commons licence and your intended use is not permitted by statutory regulation or exceeds the permitted use, you will need to obtain permission directly from the copyright holder. To view a copy of this licence, visit http://creativecommons.org/licenses/by/4.0/.

\section{References}

Adams, G. A., \& Jex, S. M. (1999). Relationships between time management, control, work-family, and strain. Journal of Occupational Health Psychology, 4, 72-77. 
Ala-Mursula, L., Vahtera, J., Kivimäki, M., Kevin, M., \& Pentti, J. (2002). Employee control over working times: Associations with subjective health and sickness absence. Journal of Epidemiology and Community Health, 56, 272-278.

Ala-Mursula, L., Vahtera, J., Pentti, J., \& Kivimäki, J. (2006). Effect of employee worktime control on health: A prospective cohort study. Occupational and Environmental Medicine, 61, 254-261.

Alvesson, M. (2001). Knowledge work: Ambiguity, image and identity. Human Relations, 54, 863-886.

Baird, B., Smallwood, J., Mrazek, M. D., Kam, J. W. Y., Franklin, M. S., \& Shooler, J. W. (2012). Inspired by distraction: Mind wandering facilitates creative incubation. Psychological Science, 23, 1117-1122.

Barney, C. E., \& Elias, S. M. (2010). Flex-time as a moderator of the job stress-work motivation relationship: A three nation investigation. Personnel Review, 39, 487-502.

Billett, S. (2006). Relational interdependence between social and individual agency in work and working life. Mind, Culture, and Activity, 13, 53-69.

Bizzi, L. (2017). Network characteristics. When an individual's job crafting depends on the jobs of others. Human Relations, 70, 436-460.

Blount, S., \& Janicik, G. A. (2001). When plans change: Examining how people evaluate timing changes in work organizations. Academy of Management Review, 26, 566-585.

Brinkley, I., Fauth, R., Mahdon, M., \& Theodoropoulou, S. (2009). Knowledge workers and knowledge work. London. The Work Foundation.

Carayon, P. (1993). Longitudinal test of Karasek's job strain model among office workers. Work \& Stress, 7 , $104-118$.

Catanzaro, M. (1988). Using qualitative analytical techniques. Using qualitative analytical techniques. In P. Woods \& M. Catanzaro (Eds.), Nursing research; theory and practice (pp. 437-456). New York: C.V. Mosby Company.

Chesley, N. (2014). Information and communication technology use, work intensification and employee strain and distress. Work, Employment and Society, 28, 589-610.

Cipriani, R. (2013). The many faces of social time: A sociological approach. Time \& Society, 22, 5-30.

de Jong, J., Mulder, M. J. G. P., \& Nijhuis, F. (1999). The incorporation of different demand concepts in the job demand-control model: Effects on health care professionals. Social Science \& Medicine, 48, 11491160.

De Spiegelaere, S., Van Gyes, G., \& Van Hootegem, G. (2016). Not all autonomy is the same. Different dimensions of job autonomy and their relation to work engagement and innovative work behavior. Human Factors and Ergonomics in Manufacturing \& Service Industries, 26, 515-527.

Demerouti, E., Bakker, A. B., Nachreiner, F., \& Schaufeli, W. B. (2001). The job demands-resources model of burnout. Journal of Applied Psychology, 86, 499-512.

Ehrenberg, A. (2010). The weariness of self. Diagnosing the history of depression in the contemporary age. Montreal \& Kingston: McGill-Queen's University Press.

Elo, S., \& Kyngäs, H. (2007). The qualitative content analysis process. Journal of Advanced Nursing, 62, $107-115$.

Flaherty, M. G., \& Seipp-Williams, L. (2005). Sociotemporal rhythms in e-mail. A case study. Time \& Society, 14, 39-49.

Frankenhaeuser, M., \& Gardell, B. (1976). Underload and overload in working life: Outline of a multidisciplinary approach. Journal of Human Stress, 2, 35-46.

Frese, M. (1989). Theoretical models of control and health. In I. S. L. Sauter, J. J. Hurrell, \& C. L. Cooper (Eds.), Job control and worker health (pp. 107-128). New York, NY: Wiley.

Gardell, B. (1971). Alienation and mental health in the modern industrial environment. In L. Levi (Ed.), Society, stress and disease, The psychosocial environment and psychosomatic diseases (Vol. 1, pp. 148180). London: Oxford University Press.

Hackman, J. R., \& Oldham, G. R. (1975). Development of the job diagnostic survey. Journal of Applied Psychology, 60, 159-170.

Hakkarainen, K., Lallimo, J., \& Toikka, S. (2012). Asiantuntijuus, kollektiivinen luovuus, ja jaetut tietokäytännöt. Aikuiskasvatus, 32, 246-256.

Heikkilä, K., Fransson, E. I., Nyberg, S. T., Zins, M., Westerlund, H., Westerholm, P., \& for the IPD-Work Consortium. (2013). Job strain and health-related lifestyle: Findings from an individual-participant metaanalysis of 118000 working adults. American Journal of Public Health, 103, 2090-2097.

Hellgren, J., Sverke, M., \& Näswall, K. (2008). Changing work roles: New demands and challenges. In K. Näswall, J. Hellgren, \& M. Sverke (Eds.), The individual in the changing working life (pp. 46-66). Cambridge: Cambridge University Press.

Hernes, T. (2004). Studying composite boundaries: A framework of analysis. Human Relations, 57, 9-29. 
Karasek Jr., R. A. (1979). Job demands, job decision latitude, and mental strain: Implications for job redesign. Administrative Science Quarterly, 24, 285-308.

Ketokivi, K. (2014). Sidoksen kysymys sosiologisessa ajattelussa ja läheissuhteiden tutkimuksessa. Sosiologia, 51, 139-154.

Kivimäki, M., Nyberg, S., Batty, G. D. [...], for the IPD-Work Consortium. (2012). Job strain as a risk factor for coronary heart disease: A collaborative meta-analysis of individual participant data. Lancet, 380, 1491-1497.

Kompier, M. (2003). Job design and well-being. In M. Schabracq, J. A. M. Winnubst, \& C. L. Cooper (Eds.), The handbook of work and health psychology (pp. 429-454). Chichester: John Wiley \& Sons Ltd..

Langfred, C. W., \& Rockmann, K. W. (2016). The push and pull of autonomy. The tension between individual autonomy and organizational control in knowledge work. Group \& Organization Management, 41, 629657.

Lee, H., \& Sawyer, S. (2010). Conceptualizing time, space and computing for work and organizing. Time \& Society, 19, 293-317.

Lewis, J. D., \& Weigert, A. J. (1981). The structures and meanings of social time. Social Forces, 60, 432-462.

Liao, T. F., Beckman, J., Marzolph, E., Riederer, C., Sayler, J., \& Schmelkin, L. (2013). The social definition of time for university students. Time \& Society, 22, 119-151.

Little, L. M., Major, V. S., Hinojosa, A. S., \& Nelson, D. L. (2015). Professional image maintenance: How women navigate pregnancy in the workplace. Academy of Management Journal, 58, 8-37.

Liu, C., Spector, P. E., Liu, Y. \& Shi, L. (2011). The interaction of job autonomy and conflict with supervisor in China and the United States: A qualitative and quantitative comparison. International Journal of Stress Management, 18, 222-245.

Locke, L. (2001). Grounded theory in management research. London: Sage.

Madsen, I. E. A., Nyberg, S. T., Magnusson Hanson, L. L., Ferrie, J., Ahola, K., Alfredsson, L. et al. with IPDwork consortium (2017). Job strain as a risk factor for clinical depression: systematic review and metaanalysis with additional individual participant data. Psychological Medicine, 47, 1342-1356.

Mazmanian, M., Orlikowski, W., \& Yates, J. A. (2013). The autonomy paradox: The implications of mobile email devices for knowledge professionals. Organization Science, 24, 1337-1357.

Moen, P., Kelly, E. L., Tranby, E., \& Huang, Q. (2011). Changing work, changing health: Can real work-time flexibility promote health behaviors and well-being? Journal of Health and Social Behavior, 52, 404-429.

Moen, P., Kelly, E. L., \& Lam, J. (2013). Healthy work revisited: Do changes in time strain predict well-being. Journal of Occupational Health Psychology, 18, 157-172.

Morgeson, F. P., \& Humphrey, S. E. (2006). The work design questionnaire (WDQ): Developing and validating a comprehensive measure for assessing job design and the nature of work. Journal of Applied Psychology, 91, 1321-1339.

Muntaner, C., \& O'Campo, P. J. (1993). A critical appraisal of the demand/control model of the psychosocial work environment. Epistemological, social, behavioral and class considerations. Social Science \& Medicine, 36, 1509-1517.

Näswall, K., Hellgren, J., \& Sverke, M. (2008). The individual in the changing working life: Introduction. In K. Näswall, J. Hellgren, \& M. Sverke (Eds.), The individual in the changing working life (pp. 1-16). Cambridge: Cambridge University Press.

Nätti, J., Tammelin, M., Anttila, T., \& Ojala, S. (2011). Work at home and time use in Finland. New Technology, Work and Employment, 26, 68-77.

Newton, T. (1995). 'Managing' stress: Emotion and power at work. London: Sage.

Nijp, H. H., Beckers, D. G. J., Geurts, S. A. E., Tucker, P., \& Kompier, M. A. J. (2012). Systematic review on the association between employee worktime control and work-non-work balance, health and well-being, and job-related outcomes. Scandinavian Journal of Work, Environment and Health, 38, 299-313.

Noonan, J. (2015). Thought-time, money-time, and the temporal conditions of academic freedom. Time \& Society, 24, 109-128.

Orlikowski, W. J., \& Yates, J. A. (2002). It's about time: Temporal structuring in organizations. Organization Science, 13, 684-700.

Parker, S. K., Andrei, D., \& Li, W. D. (2014). An overdue overhaul: Revamping work design theory from a time perspective. In A. Shipp \& Y. Fried (Eds.), Time and work: How time impacts individuals (pp. 191209). New York, NY: Psychology Press.

Payne, G., \& Williams, M. (2005). Generalization in qualitative research. Sociology, 39, 295-314.

Rosa, H. (2003). Social acceleration: Ethical and political consequences of a desynchronized high-speed society. Constellations. An International Journal of Critical and Democratic Theory Jg., 10, 3-52. 
Rugulies, R., Martin, M. H. T., Garde, A. H., Persson, R., \& Albertsen, K. (2012). Deadlines at work and sleep quality. Cross-sectional and longitudinal findings among Danish knowledge workers. American Journal of Industrial Medicine, 55, 260-269.

Schaufeli, W., \& Taris, T. (2014). A critical review of the job demands-resources model: Implications for improving work and health. In G. F. Bauer \& O. Hämmig (Eds.), Bridging occupational, organizational and public health. A Transdisciplinary approach (pp. 43-68). Dordrecht: Springer.

Schonfeld, I. S., \& Mazzola, J. J. (2012). Strengths and limitations of qualitative approaches to research in occupational health psychology. In R. R. Sinclair, M. Wang, \& L. E. Tetrick (Eds.), Research methods in occupational health psychology (pp. 268-289). New York: Routledge.

Schwartz, B. (2005). The paradox of choice: Why more is less - how the culture of abundance robs us of satisfaction. New York, NY: Harper Perennial.

Shultz, K., Wang, S., M., \& Olson, D. A. (2010). Role overload and underload in relation to occupational stress and health. Stress \& Health, 26, 99-111.

Silverman, D. (2001). Interpreting qualitative data. Methods for analyzing talk, text and interaction. 2 nd ed. London: Sage.

Slawinski, N., \& Bansal, P. (2015). Short on time: Intertemporal tensions in business sustainability. Organization Science, 26, 531-549.

Smollan, R. K., Sayers, J. G., \& Matheny, J. A. (2010). Emotional responses to the speed, frequency and timing of organizational change. Time \& Society, 19, 28-53.

Southerton, D. (2006). Analysing the temporal Organization of Daily Life: Social constraints, practices and their allocation. Sociology, 40, 435-454.

Southerton, D. (2012). Habits, routines and temporalities of consumption: From individual behaviours to the reproduction of everyday practices. Time \& Society, 22, 335-355.

Statistics Finland. (2016). FLEED Data. Finnish Longitudinal Employer-Employee Data. Helsinki: Statistics Finland.

Stiglbauer, B., \& Kovacs, C. (2018). The more, the better? Curvilinear effects of job autonomy on well-being from vitamin model and PE-fit theory perspectives. Journal of Occupational Health Psychology, 23, 520536.

Strauss, A. \& Corbin, J. (1998). Basics of qualitative research. Procedures and techniques for developing grounded theory. Thousand Oaks, CA. SAGE.

Sutela, H., \& Lehto, A. M. (2014). Työolojen muutokset 1977-2013. Helsinki: Statistics Finland.

Swanberg, J. E., McKechnie, S. P., Ojha, M. U., \& James, J. B. (2011). Schedule control, supervisor support and work engagement: A winning combination for workers in hourly jobs? Journal of Vocational Behavior, 79, 613-624.

Toivanen, M., Yli-Kaitala, K., Viljanen, O., Väänänen, A., Turpeinen, M., Janhonen, M. \& Koskinen, A. (2016). AikaJärjestys asiantuntija työssä. [in English: (A)synchrony of timelines among professionals]. Helsinki: Finnish institute of Occupational Health.

Väänänen, A., \& Toivanen, M. (2018). The challenge of tied autonomy for traditional work stress models. Work \& Stress, 32, 1-5.

Von Nordenflycht, A. (2010). What is a professional service firm? Toward a theory and taxonomy of knowledge-intensive firms. Academy of Management Review, 35, 155-174.

Wajcman, J., \& Rose, E. (2011). Constant connectivity: Rethinking interruptions at work. Organization Studies, 32, 941-961.

Wilhelmy, A., Kleinmann, M., König, C. J., Melchers, K. G., \& Truxillo, D. M. (2016). How and why do interviewers try to make impressions on applicants? A qualitative study. Journal of Applied Psychology, $101,313-332$.

Zumbrum, J. (2016). The rise of knowledge workers is accelerating despite the threat of automation. The Wall Street Journal, (May 4).

Publisher's Note Springer Nature remains neutral with regard to jurisdictional claims in published maps and institutional affiliations. 